[Chem. Pharm. Bull.

35( 1) $188-194$ (1987)

\title{
Two-Dimensional Nuclear Magnetic Resonance Spectra of Selected Tricyclic Antidepressants
}

\author{
David J. Craik, ${ }^{*}$ Jon G. Hall and Sharon L. A. Munro \\ School of Pharmaceutical Chemistry, Victorian College of Pharmacy Ltd., \\ 381 Royal Parade, Parkville, Victoria, Australia 3052
}

(Received July 23, 1986)

\begin{abstract}
Two-dimensional nuclear magnetic resonance (2D NMR) spectroscopy has been used to assign ${ }^{13} \mathrm{C}$ spectra of the tricyclic antidepressants imipramine and chlorimipramine. The 2DINADEQUATE method was used to unambiguously assign the aromatic spectral region for the former compound. Errors in previous literature assignments based on 1D methods were corrected. For chlorimipramine the pitfalls of classical substituent chemical shift arguments for ${ }^{13} \mathrm{C}$ assignments and the difficulties of $1 \mathrm{D}$ selective ${ }^{1} \mathrm{H}$ irradiation in overlapped systems are contrasted with the power and relative simplicity of the $2 \mathrm{D}-{ }^{13} \mathrm{C},{ }^{1} \mathrm{H}$-correlated and ${ }^{13} \mathrm{C},{ }^{1} \mathrm{H}$ RELAY methods.
\end{abstract}

Keywords-NMR; 2D NMR; imipramine; chlorimipramine; antidepressants; spectral assignment; ${ }^{13} \mathrm{C}-\mathrm{NMR}$

\section{Introduction}

Tricyclic antidepressants (TCA's) are widely used in the treatment of depression. This action is thought to be related, at least in part, to their ability to inhibit re-uptake of amine neurotransmitters into presynaptic nerve endings, although the detailed mechanism by which TCA's exert their effects remains unknown. Nuclear magnetic resonance (NMR) spectroscopy has the potential to increase our knowledge of the molecular events involved in antidepressant action, since it provides a means of examining interactions between drugs and membranes or receptor proteins. ${ }^{1)}$ However, before such studies can be contemplated a thorough understanding of the solution properties and spectral assignments of the antidepressants is required. Unfortunately, some of the early studies in this area ${ }^{2,3)}$ have been marred by incorrect assignments due largely to the inadequacies of conventional assignment techniques. In this paper these errors are corrected and the power of modern two-dimensional (2D) methods in the assignment of ${ }^{1} \mathrm{H}$ - and ${ }^{13} \mathrm{C}-\mathrm{NMR}$ spectra of representative antidepressants is discussed.

The 2D NMR methods of interest are 2D-INADEQUATE, ${ }^{4}$ carbon-hydrogen correlated spectroscopy ${ }^{5)}$ and carbon-hydrogen relayed coherence transfer (RELAY). ${ }^{6}$

The 2D-INADEQUATE ${ }^{4)}$ experiment is potentially the most powerful technique available for deducing connectivities in molecular frameworks as it provides direct detection of one-bond carbon-carbon couplings. Such couplings are observable only in molecules containing two adjacent ${ }^{13} \mathrm{C}$ nuclei (i.e., 1 in every 10000 molecules at natural abundance) and thus in a conventional ${ }^{13} \mathrm{C}$ spectrum would appear as satellite signals centred about the hundred-fold stronger resonance arising from molecules containing a single ${ }^{13} \mathrm{C}$ nucleus. Limitations of dynamic range and resolution make observation of these satellite signals difficult in practical cases, except with a technique such as INADEQUATE, ${ }^{7)}$ which uses phase cycling of the applied radio frequency pulses to suppress the strong central band. For carbons attached to more than one other carbon, significant overlap of the separate satellites 
could be expected in a $1 \mathrm{D}$ experiment, but in the 2D-INADEQUATE method an appropriate pulse sequence separates the satellites according to the double quantum frequency of the coupled nuclei. The resultant $2 \mathrm{D}$ spectrum has the carbon chemical shift as one axis $\left(\mathrm{F}_{2}\right)$ and the double quantum frequency, which is the sum of the chemical shifts of the coupled nuclei (relative to the carrier frequency) as the second axis $\left(\mathrm{F}_{1}\right)$. While this technique provides very direct connectivity information, it has the disadvantage of being time-consuming in terms of data acquisition because only molecules containing two adjacent ${ }^{13} \mathrm{C}$ nuclei are detected.

The heteronuclear shift-correlated $2 \mathrm{D}$ pulse experiment provides a rapid method for correlating the chemical shift of proton-bearing carbons with the chemical shift of their respective protons. Heteronuclear shift-correlated $2 \mathrm{D}$ spectra are normally represented in contour form, with the ${ }^{13} \mathrm{C}$ chemical shift $(\delta \mathrm{C})$ along the horizontal $\left(\mathrm{F}_{2}\right)$ axis and the proton chemical shift $(\delta \mathrm{H})$ along the vertical $\left(\mathrm{F}_{1}\right)$ axis. Correlations appear at $(\delta \mathrm{C}, \delta \mathrm{H})$. A major advantage of this method is that it uses the carbon chemical shift dispersion to resolve the proton spectrum and in so doing, it has the potential to reveal overlapping proton multiplicities and coupling constants.

Detection of remote carbon-proton connectivities may be achieved by the $2 \mathrm{D}$ technique of relayed coherence transfer heteronuclear correlated spectroscopy (RELAY). The resultant 2D spectrum correlates the chemical shifts of ${ }^{13} \mathrm{C}$ nuclei (along the $\mathrm{F}_{2}$ axis) with the ${ }^{1} \mathrm{H}$ chemical shifts of both directly coupled neighbouring protons and the remote protons which are coupled to the neighbouring protons. The $2 \mathrm{D}$ spectrum therefore displays not only neighbouring cross-peaks of two protonated carbons, $\mathrm{A}$ and $\mathrm{B}$, at $\left(\delta \mathrm{C}_{\mathrm{A}}, \delta \mathrm{H}_{\mathrm{A}}\right)$ and $\left(\delta \mathrm{C}_{\mathrm{B}}, \delta \mathrm{H}_{\mathrm{B}}\right)$, similar to the $\mathrm{CH}$ correlated $2 \mathrm{D}$ spectrum, but in addition relayed cross-peaks at $\left(\delta \mathrm{C}_{\mathrm{A}}, \delta \mathrm{H}_{\mathrm{B}}\right)$ and $\left(\delta \mathrm{C}_{\mathrm{B}}, \delta \mathrm{H}_{\mathrm{A}}\right)$. These four signals appear at the corners of a rectangle in the $2 \mathrm{D}$ spectrum and provide evidence that the two carbon signals at $\delta \mathrm{C}_{\mathrm{A}}$ and $\delta \mathrm{C}_{\mathrm{B}}$ are from sites in the immediate vicinity of each other within the molecular framework. The method thus directly provides connectivity information, as does 2D-INADEQUATE, but is more sensitive since it does not rely on natural abundance double- ${ }^{13} \mathrm{C}$ labelling.

\section{Experimental}

Materials - Imipramine hydrochloride was a generous gift from Ciba-Geigy. Chlorimipramine hydrochlodride was kindly donated by Dr. D. Taylor, Victorian College of Pharmacy Ltd. Deuteriochloroform (99.8\% D) was supplied by Aldrich Chemical Co., Michigan, U.S.A.

NMR Spectroscopy $-{ }^{1} \mathrm{H}$ - and ${ }^{13} \mathrm{C}$-NMR spectra were recorded on a Bruker AM $300 \mathrm{WB}$ spectrometer operating at 300.13 and $75.48 \mathrm{MHz}$ respectively. Fourier transform (FT) ${ }^{1} \mathrm{H}-\mathrm{NMR}$ spectra were normally recorded with a $60^{\circ}$ pulse $(3 \mu \mathrm{s})$, repetition time $3 \mathrm{~s}$, spectral width $3 \mathrm{kHz}$, and $16 \mathrm{k}$ data points. 16 transients were accumulated. Chemical shifts are referenced to the residual chloroform resonance at 7.24 parts per million (ppm).

$1 \mathrm{D}{ }^{13} \mathrm{C}$-NMR spectra were obtained with a $45^{\circ}$ pulse $(6 \mu \mathrm{s})$, repetition time $2 \mathrm{~s}$, spectral width $16 \mathrm{kHz}$ and $8 \mathrm{~K}$ data points. Proton decoupling was achieved using low-power Waltz decoupling. ${ }^{8}$ Free-induction decays (FID's) were zero-filled to $16 \mathrm{~K}$ data points, and $2 \mathrm{~Hz}$ exponential line-broadening was applied before Fourier transformation. Chemical shifts were referenced to the centre peak of deuteriochloroform at $77.0 \mathrm{ppm}$.

2D-INADEQUATE spectra ${ }^{4)}$ were obtained with the pulse sequence $90^{\circ}-\tau-180^{\circ}-\tau-90^{\circ}-t_{1}-135^{\circ}$ FID $\left(t_{2}\right)$ with spectral widths $F_{1}=5000, F_{2}=2500 \mathrm{~Hz}$, a $90^{\circ}$ pulse of $13.5 \mu \mathrm{s}$, quadrature detection in both dimensions, Waltz proton decoupling, $\tau=1 / 4 \mathrm{~J}(\mathrm{C}-\mathrm{C})=4.2 \mathrm{~ms}$, a repetition time of $1.2 \mathrm{~s}$, a $128 \times 2048$ word data matrix, and a total acquisition time of $12 \mathrm{~h}$. The data was processed as a $256 \times 2048$ word data matrix with a sine-bell window function in both dimensions.

The $2 \mathrm{D}-{ }^{1} \mathrm{H},{ }^{13} \mathrm{C}$ CORRELATED spectra ${ }^{5)}$ were acquired with the pulse sequence

$$
\begin{array}{cccc}
{ }^{1} \mathrm{H}: & 90-t_{1} / 2--t_{1} / 2-\tau_{1}-90-\tau_{2}-\text { Waltz decoupling } \\
{ }^{13} \mathrm{C}: & 180 & 90 & \text {-FID }\left(t_{2}\right)
\end{array}
$$

with spectral widths $F_{1} \pm 100 \mathrm{~Hz}, \mathrm{~F}_{2}=2000 \mathrm{~Hz}$, quadrature detection in both dimensions, $\tau_{1}=\tau_{2}=1 / 2 \mathrm{~J}(\mathrm{CH})=3 \mathrm{~ms}$, a $128 \times 2048$ word data matrix, and a repetition time of $4 \mathrm{~s}$. The data were processed as a $512 \times 2048$ word data matrix with a sine-bell window in $F_{1}$ and $2 \mathrm{~Hz}$ exponential line-broadening in $F_{2}$. 
The $2 \mathrm{D}-{ }^{1} \mathrm{H},{ }^{1} \mathrm{H},{ }^{13} \mathrm{C}$ RELAYED spectra ${ }^{6)}$ were acquired with the pulse sequence

$$
\begin{aligned}
& { }^{1} \mathrm{H}: 90-t_{1} / 2--t_{1} / 2-90-t_{\mathrm{m}} / 2-180-t_{\mathrm{m}} / 2-\tau_{1}-90-\tau_{2} \text {-Waltz decoupling } \\
& { }^{13} \mathrm{C}: \quad 180 \\
& 90
\end{aligned}
$$

with the same spectral and acquisition parameters used in the ${ }^{1} \mathrm{H},{ }^{13} \mathrm{C}$ correlated spectra. The mixing time, $t_{\mathrm{m}}$, was $16 \mathrm{~ms}$ and total acquisition time $15 \mathrm{~h}$. The data were processed as a $256 \times 2048$ word data matrix with a sine-bell window in $\mathrm{F}_{1}$ and a $2 \mathrm{~Hz}$ exponential line-broadening in $\mathrm{F}_{2}$.

\section{Results and Discussion}

Imipramine (1) was the first of the TCA's to be developed and it is still in widespread clinical use.

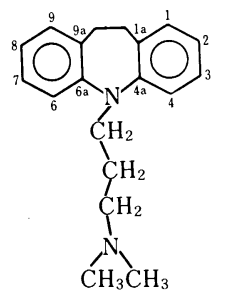

Its ${ }^{13} \mathrm{C}$-NMR spectrum in the aromatic region is shown in Fig. 1 with proposed assignments of Abraham et al. ${ }^{2)}$ and Saito and coworkers. ${ }^{1)}$ The original assignments of Abraham, which were presumably based on model compounds, appear to be plausible; however, very recently Saito and coworkers used selective ${ }^{1} \mathrm{H}$ decoupling to reassign the ${ }^{13} \mathrm{C}$ shifts for protonated carbons. In this technique each proton is separately irradiated during acquisition of the ${ }^{13} \mathrm{C}$ spectrum and hence only the carbon attached to the irradiated proton appears as a sharp singlet. Other carbons are only partially decoupled and appear as multiplets or broadened peaks. The results of these experiments suggested that the original $C_{2}$ and $C_{4}$ assignments should be reversed.

This ${ }^{13} \mathrm{C}$ assignment technique of course requires a prior assignment of the aromatic region of the ${ }^{1} \mathrm{H}-\mathrm{NMR}$ spectrum, which in the case of imipramine consists of two doublets and two triplets due to ortho coupling (meta coupling was not resolved in the spectra shown by Saito and coworkers). The doublets were assigned to $\mathrm{H}_{1}$ and $\mathrm{H}_{4}$ and the connectivity of the peaks was determined by selective ${ }^{1} \mathrm{H}$ homonuclear decoupling. To complete the assignment a determination of which of the doublets was $\mathrm{H}_{1}$ and which $\mathrm{H}_{4}$ was required, and this was made from chemical shift arguments relating to the central nitrogen's effect on $\mathrm{H}_{1}$. Such arguments must, however, be used with caution since the substituent effect of a nitrogen varies markedly with its state of protonation (e.g., $\mathrm{NH}_{2}$ induces an upfield shift of $-0.8 \mathrm{ppm}$ at the ortho proton in aniline relative to benzene, while for $\mathrm{NH}_{3}^{+}$the shift is opposite in sign, +0.4 ppm..$^{9}$ To some extent this ambiguity was resolved by noting that on treatment with $\mathrm{DCl}$, the ${ }^{1} \mathrm{H}$ NMR signals from $\mathrm{H}_{2}$ and $\mathrm{H}_{4}$ disappeared, as expected for sites ortho and para to the nitrogen, but again this relies on assumptions about the chemical-directing effect of this group, which may well change with protonation.

Another difficulty with Saito's assignment is that $\mathrm{C}_{1 \mathrm{a}}$ is shown to be the most downfield peak, in contrast to Abraham's assignment and to expectations based on the inductive effect of the nitrogen having its major effect on $\mathrm{C}_{4 \mathrm{a}}$. In Saito and coworkers' discussion of this assignment, it was suggested that the peak assigned to $\mathrm{C}_{1 \mathrm{a}}$ is broadened by unresolved longrange coupling to the benzylic bridge protons. While this is reasonable, it would be equally valid to argue that $\mathrm{C}_{4 \mathrm{a}}$ should be broadened due to rapid quadrupolar relaxation of the adjacent nitrogen, and hence peak broadening cannot be used as an assignment criterion. 
To overcome the difficulties noted above, and to resolve the anomalies in the two literature assignments of imipramine, we have applied a technique which requires no assumptions and does not require specific isotope labelling. This is the 2D-INADEQUATE method. A contour plot of the 2D-INADEQUATE spectrum for the aromatic region of imipramine is shown in Fig. 2. In this figure the $F_{2}$ dimension shows pairs of AX doublets arising from molecules containing two adjacent ${ }^{13} \mathrm{C}$ nuclei, while the $\mathrm{F}_{1}$ dimension resolves these doublet pairs according to their double quantum frequency (equal to the sum of the shifts of $\mathrm{A}$ and $\mathrm{X}$ with respect to the radio frequency carrier).

The assignment proceeds by noting that the only doublet (marked $X$ on Fig. 2) which has a coupling partner outside the spectral range must be $\mathrm{C}_{1 \mathrm{a}}$, since it is the only aromatic carbon coupled to an aliphatic carbon. In addition, this peak shows couplings to two aromatic carbons, one of which is a quaternary carbon and thus must be $\mathrm{C}_{4 \mathrm{a}}$, and the other is thus $\mathrm{C}_{1}$. The coupling network can be further traced around the ring, as shown in the figure, to provide a completely unambiguous assignment. Our results show that the assignments of Saito et al. are correct for the protonated aromatic carbons but that the non-protonated aromatic carbon assignments should be reversed to correspond with the original assignment of Abraham et al. The correct assignments are summarized in Fig. 1.

Imipramine represents a favourable case for the 2D-INADEQUATE experiment in that it has a low molecular weight and is relatively soluble, so that sensitivity problems can be
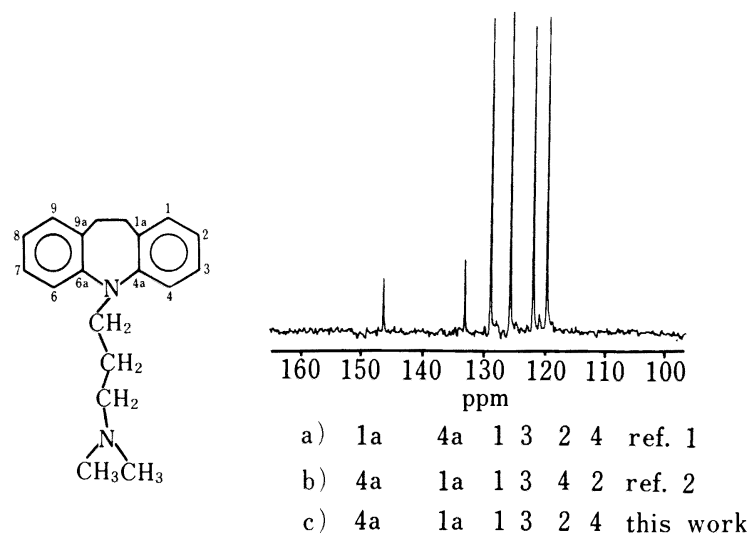

Fig. 1. The Aromatic Region of the ${ }^{13} \mathrm{C}-\mathrm{NMR}$ Spectrum of Imipramine with Proposed Assignments of (a) Saito and Coworkers, ${ }^{1)}$ (b) Abraham et al., ${ }^{2)}$ and (c) This Work Based on the 2D-INADEQUATE Technique

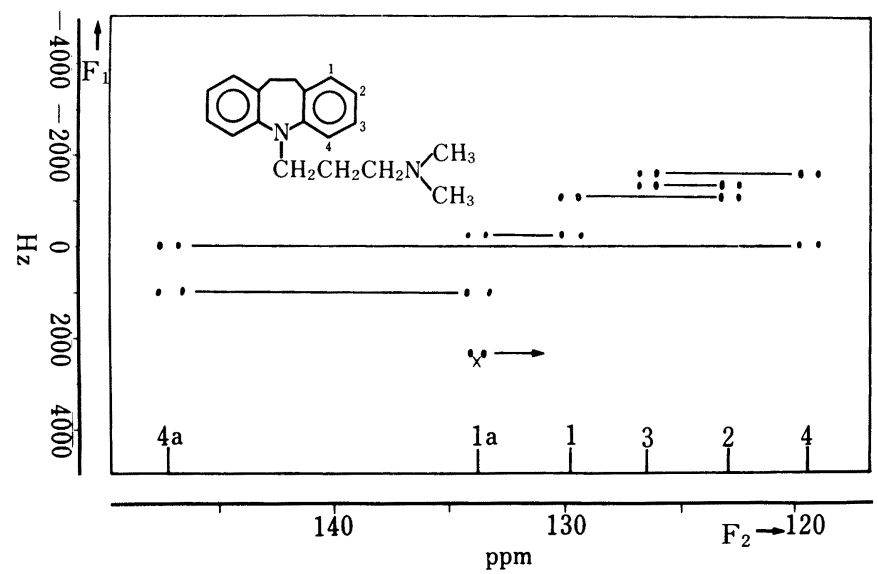

Fig. 2. 2D-INADEQUATE ${ }^{13} \mathrm{C}$ Spectrum of the Aromatic Region of Imipramine 
TABLE I. Predicted ${ }^{13} \mathrm{C}$ Shifts for Chlorimipramine

\begin{tabular}{ccccc}
\hline \hline $\begin{array}{c}\text { Carbon } \\
\text { number }\end{array}$ & $\begin{array}{c}\text { Imipramine } \\
\text { shifts (ppm) }\end{array}$ & $\begin{array}{c}\text { Cl-SCS } \\
(\mathrm{ppm})\end{array}$ & $\begin{array}{c}\text { Predicted } \\
\text { chlorimipramine } \\
\text { shifts (ppm) }\end{array}$ & $\begin{array}{c}\text { Observed } \\
\text { chlorimipramine } \\
\text { shifts (ppm) }\end{array}$ \\
\hline 1 & 129.9 & 1.3 & 131.2 & 131.4 \\
2 & 123.1 & 0.4 & 123.5 & 122.7 \\
3 & 126.5 & 6.2 & 132.7 & 131.4 \\
4 & 119.5 & 0.4 & 119.9 & 119.4 \\
6 & 119.5 & - & 119.5 & 120.2 \\
7 & 126.5 & - & 126.5 & 126.8 \\
8 & 123.1 & - & 123.1 & 124.0 \\
9 & 129.9 & -1.9 & 129.9 & 129.7 \\
$1 \mathrm{a}$ & 133.9 & 1.3 & 132.0 & 131.7 \\
$4 \mathrm{a}$ & 147.1 & - & 148.4 & 148.2 \\
$6 \mathrm{a}$ & 147.1 & - & 147.1 & 146.5 \\
$9 \mathrm{a}$ & 133.9 & 133.9 & 134.9 \\
\hline
\end{tabular}
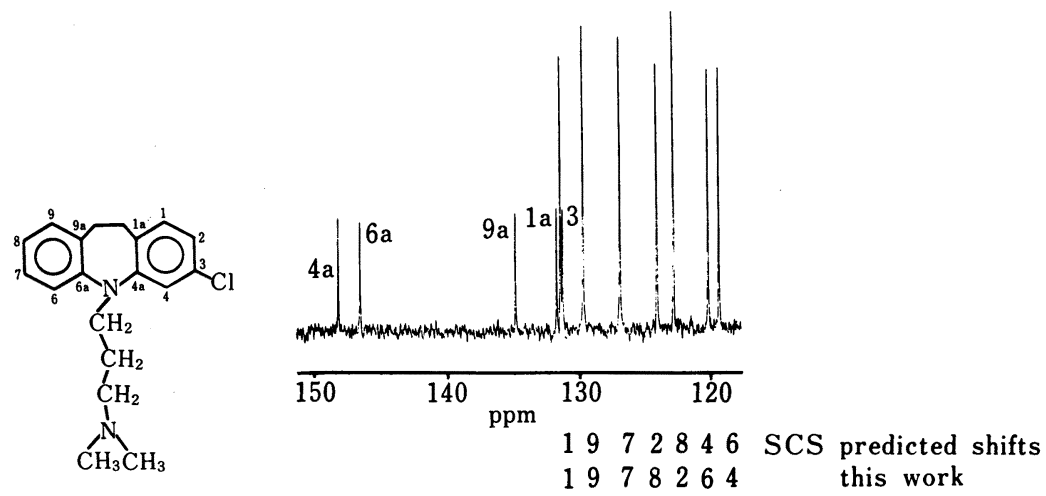

Fig. $3 .{ }^{13} \mathrm{C}-\mathrm{NMR}$ Spectrum of the Aromatic Region of Chlorimipramine

alleviated by using relatively concentrated solutions. (In the case above the concentration was $150 \mathrm{mg} / \mathrm{ml}$.) The symmetry of the molecule on the NMR time-scale also doubles the effective concentration of each aromatic carbon, thus reducing the accumulation time by a factor of four relative to a similarly sized non-symmetrical TCA such as chlorimipramine.

In this case, the relative insensitivity of the 2D-INADEQUATE technique is compounded by chlorimipramine's lower solubility relative to imipramine and thus alternative assignment methods are of interest. The usual technique for assignment of a substituted derivative when that of the parent is available, as in this case, is the use of substituent chemical shifts ${ }^{10)}$ (SCS) to predict ${ }^{13} \mathrm{C}$ shifts in the substituted derivative. Using standard SCS values (derived from chlorobenzene) for a $\mathrm{Cl}$ substituent, the predicted shifts for chlorimipramine are shown in Table I. It can be seen that predicted shifts produced in this way are sufficiently close to observed shifts (Figure 3) to assign the non-protonated carbons as well as $\mathrm{C}_{1}, \mathrm{C}_{3}, \mathrm{C}_{7}$ and $\mathrm{C}_{9}$, but the pairs $\mathrm{C}_{2}, \mathrm{C}_{8}$ and $\mathrm{C}_{4}, \mathrm{C}_{6}$ remain ambiguous. Indeed, when the shifts are compared with those established to be correct by 2D NMR (see below), it is seen (Table I) that predictions that $\mathrm{C}_{2}$ should be downfield of $\mathrm{C}_{8}$, and $\mathrm{C}_{4}$ downfield of $\mathrm{C}_{6}$ are incorrect. This occurs because SCS values of a given substituent may be significantly different in a polysubstituted benzene from those in mono-substituted benzenes. ${ }^{11)}$

It is interesting to note, for example, that better predictions for $\mathrm{C}_{2}, \mathrm{C}_{8}$ and $\mathrm{C}_{4}, \mathrm{C}_{6}$ can 
be obtained by using chlorine SCS increments derived from aniline and $m$-chloroaniline. ${ }^{12)}$ These SCS values are shown in structure (2).<smiles>Nc1cccc(Cl)c1</smiles>

Using these values, the predicted shifts $\left(\mathrm{C}_{2}, 123.0 ; \mathrm{C}_{8}, 123.1 ; \mathrm{C}_{4}, 119.3 ; \mathrm{C}_{6}, 119.5\right)$ now show the correct order. Even with these improvements, however, SCS values are not generally a totally conclusive assignment aid and other methods to distinguish the pairs $\mathrm{C}_{2}, \mathrm{C}_{8}$ and $\mathrm{C}_{4}, \mathrm{C}_{6}$ are required. The $2 \mathrm{D}-{ }^{13} \mathrm{C},{ }^{1} \mathrm{H}$ correlated spectrum in Fig. 4 provides this distinction.

In the $\mathrm{F}_{1}\left({ }^{1} \mathrm{H}\right)$ dimension, $\mathrm{H}_{4}$ should be the only peak to show just meta coupling and hence this unique coupling pattern in the contour plot identifies the most upfield peak $(119.4 \mathrm{ppm})$ as being due to the carbon correlated with $\mathrm{H}_{4}$, i.e., $\mathrm{C}_{4}$. The peak at $120.2 \mathrm{ppm}$ must therefore be due to $\mathrm{C}_{6}$. Similarly, of the remaining ambiguous peaks for $\mathrm{C}_{2} / \mathrm{H}_{2}, \mathrm{C}_{8} / \mathrm{H}_{8}$ at 122.7 and $124.0 \mathrm{ppm}$, the lower field carbon signal appears as an ortho doublet with meta coupling, i.e., it is connected to $\mathrm{H}_{2}$ and is hence $\mathrm{C}_{2}$. The peak at $124.0 \mathrm{ppm}$ is thus $\mathrm{C}_{8}$.

The projection of the $2 \mathrm{D}-{ }^{13} \mathrm{C},{ }^{1} \mathrm{H}$ correlated spectrum in the proton dimension provides the conventional proton spectrum (Fig. 4), which is heavily overlapped in the $\mathrm{H}_{8}, \mathrm{H}_{1}, \mathrm{H}_{4}, \mathrm{H}_{6}$ region. This would make the traditional technique of selective ${ }^{1} \mathrm{H}$ irradiation to assign the carbon spectrum difficult and, indeed, is the reason why Saito et al. were unable to unambiguously assign the spectra of the structurally related compound chlorpromazine. The $2 \mathrm{D}-{ }^{13} \mathrm{C},{ }^{1} \mathrm{H}$-correlated technique overcomes the problem of overlap in the ${ }^{1} \mathrm{H}$ spectrum by spreading it into a second dimension based on ${ }^{13} \mathrm{C}$ chemical shifts.

It should be noted that although the $2 \mathrm{D}-{ }^{13} \mathrm{C},{ }^{1} \mathrm{H}$-correlated technique was extremely valuable in distinguishing between $\mathrm{C}_{2}$ and $\mathrm{C}_{8}$, and between $\mathrm{C}_{4}$ and $\mathrm{C}_{6}$, the assignment is not without assumption, since chemical shift arguments were used to roughly predict shifts for $\mathrm{C}_{1}$, $\mathrm{C}_{9}, \mathrm{C}_{7}, \mathrm{C}_{8} / \mathrm{C}_{2}$ and $\mathrm{C}_{6} / \mathrm{C}_{4}$. Such chemical shift arguments can break down and, for example, the $2 \mathrm{D}$-correlated spectrum alone could not be used to distinguish between $\mathrm{C}_{7}$ and $\mathrm{C}_{8}$, since both have similar ${ }^{1} \mathrm{H}$ multiplicity. In principle $1 \mathrm{D}$-selective homonuclear decoupling experiments could be used to further assign the ID proton spectrum, which would then lead to an assignment of the ${ }^{13} \mathrm{C}$ spectrum via the $2 \mathrm{D}-{ }^{13} \mathrm{C},{ }^{1} \mathrm{H}$-correlated spectrum. However, in the

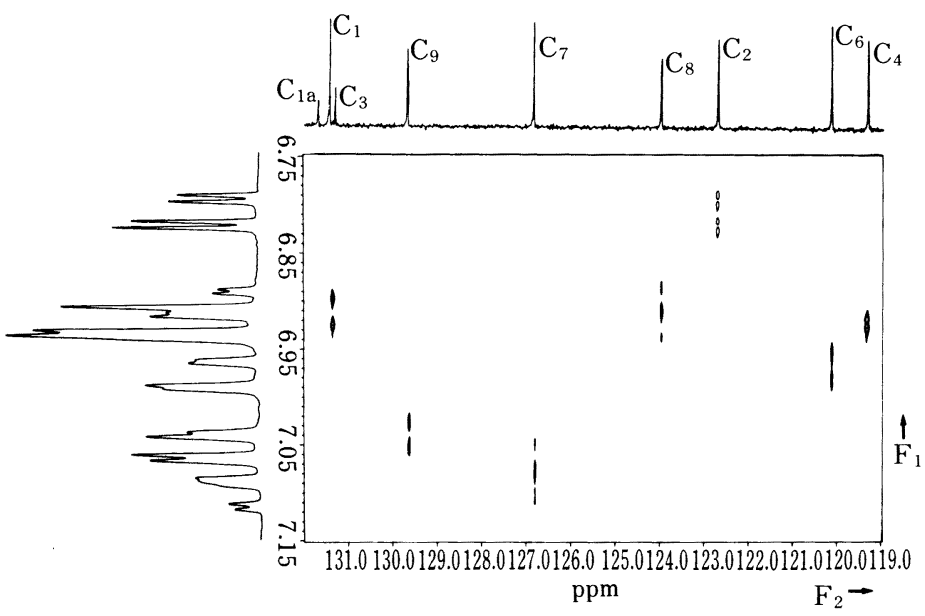

Fig. 4. 2D-Carbon-Hydrogen-Correlated Spectrum of the Aromatic Region of Chlorimipramine 


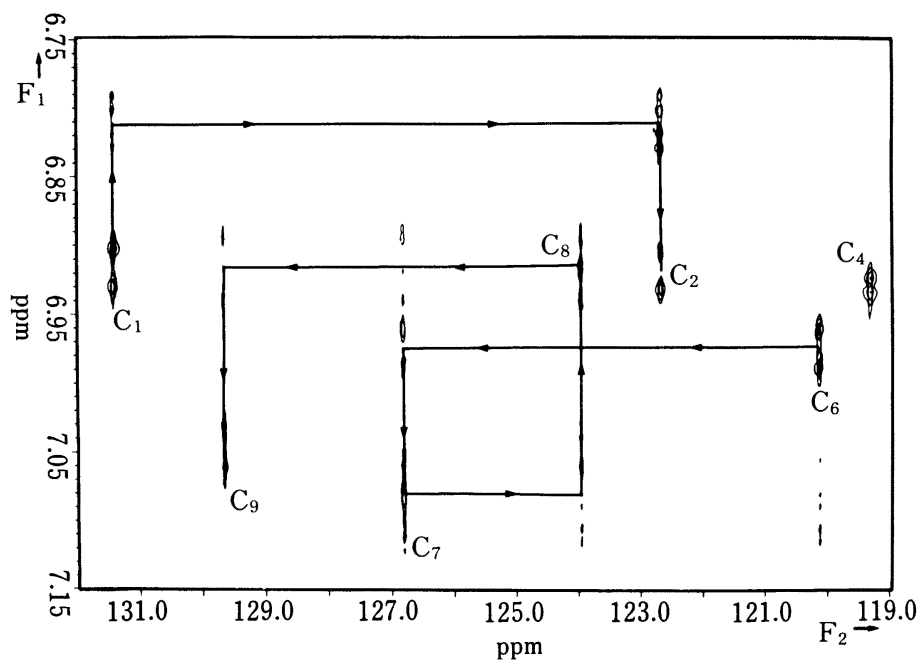

Fig. 5. 2D-RELAY Spectrum of the Aromatic Region of Chlorimipramine

current case the 1D ${ }^{1} \mathrm{H}$ spectrum is significantly overlapped, making the selective ${ }^{1} \mathrm{H}$ irradiation time-consuming and subject to substantial interpretation.

The RELAY technique can be used to overcome these difficulties and provides an assignment essentially free of assumption. The RELAY spectrum of the aromatic region of chlorimipramine shown in Fig. 5 displays all of the peaks noted in Fig. 4, but in addition contains cross-peaks indicative of two carbons sharing a common ${ }^{1} \mathrm{H}$ coupling partner. The way in which this provides connectivity information can be seen by noting that once, say, $\mathrm{C}_{6}$ is assigned, then connection to, and hence assignment of, $\mathrm{C}_{7}$, then $\mathrm{C}_{8}$, and then $\mathrm{C}_{9}$ is immediately established. Similarly, connection between the protonated carbons $\mathrm{C}_{1}$ and $\mathrm{C}_{2}$ is established.

In summary, it can be seen that even for relatively simple compounds of pharmaceutical interest, 1D methods are often inadequate for NMR spectral assignment. On the other hand, $2 \mathrm{D}$ methods are now easy to implement and have proven useful in correcting previous ambiguous assignments.

Acknowledgement This work was supported by the Australian Research Grants Scheme.

\section{References}

1) R. Tabeta, S. Mahajan, M. Maeda and H. Saito, Chem. Pharm. Bull., 33, 1793 (1985).

2) R. J. Abraham, L. J. Kricka and A. Ledwith, J. Chem. Soc., Perkin Trans. 2, 1964, 1977.

3) A. A. Al Badr, "Analytical Profiles of Drug Substances," Vol. 2, ed. by K. Florey, Academic Press, London, 1983.

4) A. Bax, R. Freeman, T. A. Frenkiel and M. H. Levitt, J. Magn. Reson., 43, 478 (1981).

5) R. Freeman and G. A. Morris, J. Chem. Soc., Chem. Commun., 1978, 684; A. A. Maudsley and R. R. Ernst, Chem. Phys. Lett., 50, 368 (1977).

6) P. H. Bolton, J. Magn. Reson., 48, 336 (1982).

7) A. Bax, R. Freeman and S. P. Kempsell, J. Am. Chem. Soc., 102, 4849 (1980).

8) A. J. Shaka, J. Keeler, T. Frenkiel and R. Freeman, J. Magn. Reson., 52, 335 (1983); idem, ibid., 53, 313 (1983).

9) D. W. Mathieson (ed.), "Nuclear Magnetic Resonance for Organic Chemists," Academic Press, New York, 1967, p. 184.

10) G. C. Levy, G. L. Nelson and R. L. Lichter, "Carbon-13 Nuclear Magnetic Resonance Spectroscopy for Organic Chemists," Wiley, New York, 1980.

11) J. Bromilow, R. T. C. Brownlee, D. J. Craik, M. Sadek and R. W. Taft, J. Org. Chem., 45, 2429 (1980).

12) J. Bromilow, R. T. C. Brownlee, D. J. Craik and M. Sadek, Magn. Reson. in Chem., 24, 862 (1986). 